\title{
PENERAPAN SISTEM INFORMASI GEOGRAFI PADA TRAFFIC MANAGEMENT CENTER
}

\author{
Michael Yoseph Ricky \\ Computer Science Department, School of Computer Science Binus University \\ Jl. K.H. Syahdan No. 9, Palmerah, Jakarta Barat 11480 \\ mricky@binus.edu
}

\begin{abstract}
This study aims to analyze and design a geographic information system as a tool for traffic flow monitoring and regulation for the Traffic Management Center Polda Metro Jaya. Data was collected through field studies relating to the engineering of software and hardware. Interviews were also conducted to the relevant parties. Then it is proceeded with systems analysis and design methods. This system succeeded in helping the Traffic Management Center to find out the points which are prone to cause congestion, so that it can quickly obtain the traffic flow information.
\end{abstract}

Keywords: geographic information system, traffic flow monitoring and regulation, Traffic Management Center, Polda Metro Jaya

\begin{abstract}
ABSTRAK
Penelitian ini bertujuan untuk menganalisis dan merancang suatu sistem informasi geografi sebagai alat bantu pemantauan dan pengaturan arus lalu lintas bagi pihak Traffic Management Center Polda Metro Jaya. Pengumpulan data dilakukan dengan studi lapangan yang berkaitan dengan dasar pembuatan software dan hardware. Wawancara juga dilakukan terhadap pihak-pihak terkait. Kemudian dilanjutkan dengan analisis sistem dan metode perancangan. Sistem ini berhasil membantu pihak Traffic Management Center untuk mengetahui titik-titik mana saja yang rawan menimbulkan kemacetan sehingga informasi mengenai arus lalu lintas dapat cepat didapatkan.
\end{abstract}

Kata kunci: sistem informasi geografi, pemantauan dan pengaturan arus lalu lintas, Traffic Management Center, Polda Metro Jaya 


\section{PENDAHULUAN}

Dalam beraktivitas kita membutuhkan sarana penunjang, salah satunya adalah kendaraan, baik bermotor maupun tidak bermotor. Seiring dengan perjalanan waktu, jumlah kendaraan semakin bertambah. Pertambahan jumlah kendaraan selayaknya diimbangi dengan pengaturan lalu lintas yang baik. Kenyataannya, kemacetan lalu lintas di kota-kota besar khususnya di Jakarta saat ini kian parah. Lampu pengatur lalu lintas yang semestinya untuk mengatur arus agar tidak terjadi simpul kemacetan, tetapi kini justru menjadi salah satu penyebab panjang antrian kendaraan. Sistem pengatur lampu lalu lintas yang saat ini digunakan kurang mampu mengatasi kemacetan. Sering terjadinya kepadatan arus lalu lintas yang semestinya mendapatkan prioritas untuk jalan malah tertahan dengan sistem yang saat ini digunakan. Akibatnya timbul antrian yang cukup panjang, sementara pada jalur lain yang tidak padat memperoleh prioritas untuk jalan lebih dulu. Hal ini disebabkan oleh sistem yang digunakan adalah sistem waktu yang sudah baku. Dengan demikian panjangnya antrian tidak menentukan urutan prioritas arus lalu lintas yang akan dijalankan.

Adapun titik kemacetan yang disebabkan oleh lampu pengatur lalu lintas atau traffic light (TL) antara lain: (1) traffic light perempatan Tomang, Jakarta Barat; (2) traffic light perempatan Harmoni, Jakarta Pusat; (3) traffic light kawasan Pondok Indah, Jakarta Selatan; (4) traffic light Perempatan Senen, Jakarta Pusat; (5) traffic light Perempatan Matraman, Jakarta Timur (sumber: Traffic Management Center).

Dalam rangka mengaplikasikan kebijakan Kapolda Metropolitan Jakarta Raya untuk meningkatkan kinerja pelayanan Polri (khususnya di bidang lalu lintas), Direktorat Lalu Lintas Polda Metropolitan Jakarta Raya berusaha membangun sarana penunjangnya (sesuai pula dengan program Kapolda Metropolitan Jakarta Raya tentang SIAP, yakni Sistem Informasi Aplikasi Polisi) yang diharapkan dapat membantu peningkatan kinerja pelayanan yang diinginkan tersebut. Sarana yang dibangun ini adalah sarana penunjang dengan menggunakan teknologi komputer yang terintegrasi dan dapat membantu kecepatan informasi yang disampaikan kepada seluruh pihak yang berkepentingan, sehingga diharapkan mampu membantu pelaksanaan tugas Polantas dalam menangani kemacetan, kecelakaan dan pelanggaran lalu lintas secara cepat dan profesional.

Sarana ini diberi nama Traffic Management Center (TMC). Pertama didirikan pada tanggal 11 april 2005 dan dipimpin oleh KADIRLANTAS (Kepala Direktorat Lalu Lintas). TMC (Traffic Management Center) merupakan pusat dari manajemen lalu lintas di polda metropolitan jakarta raya. Yang mempunyai fungsi sebagai K 3 I ( komando, komunikasi, koordinasi dan informasi ). Komando merupakan perintah dan pengedalian bagi petugas-petugas yang ada di lapangan yang rwan terjadinya masalah yang dipedomani oleh petugas di lapangan untuk mengambil tidakan-tindakan diskresi seperti pengaliran arus, memberikan prioritas dan sebagainya. Selain itu juga untuk melakukan tindakantindakan upaya paksa yang berupa pengaturan, penjagaan maupun pengawalan dan penindakan terhadap para pengguna lalu lintas yang membahayakan kesalamatan maupaun melanggar aturanaturan / hukum lalu lintas. Adapun kendali merupakan bagian dari kontrol atau pengawasan terhadap para petugas dilapangan maupaun staf dalam menjalankan operasioanal Kepolisian Direktorat Lalu Lintas Polda Metropolitan Jakarta Raya (Ditlantas Polda Metro Jaya). Gambar 1 merangkum alur sistem operasional TMC yang sedang berjalan. 


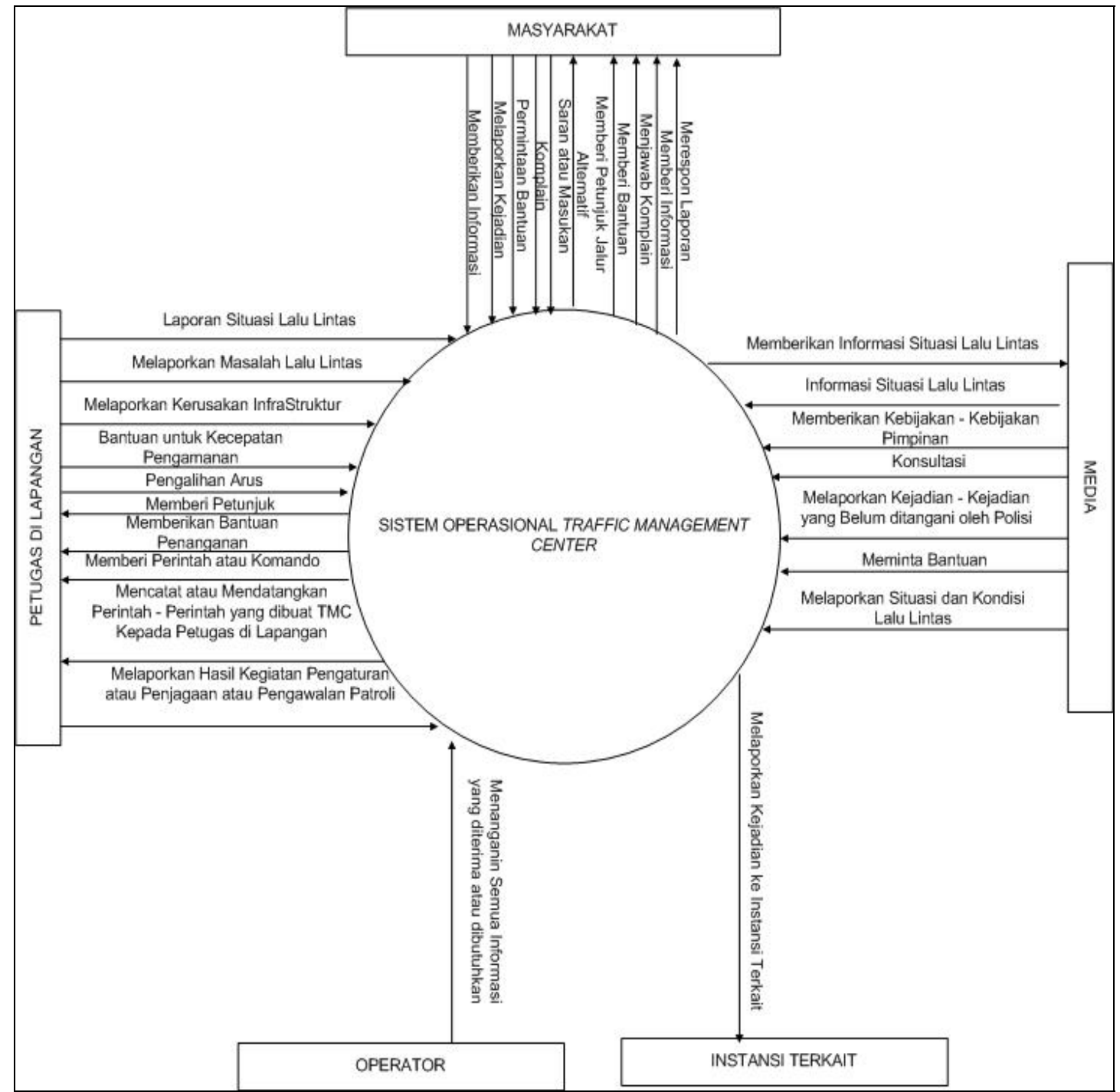

Gambar 1. Data flow diagram sistem yang sedang berjalan.

Permasalahan yang dihadapi Traffic Management Center antara lain: (1) TMC tidak dapat mengendalikan lampu pengatur lalu lintas secara langsung. Pengendalian lampu pengatur lalu lintas belum dapat dilakukan secara langsung melainkan memberikan perintah kepada petugas dilapangan untuk mengendalikan arus lalu lintas; (2) Informasi yang diberikan TMC kepada masyarakat terbatas; (3) TMC hanya dapat memberikan informasi melalui media cetak dan media elektronik sehingga informasi tersebut tidak langsung diterima oleh pengguna jalan; (4) Sistem informasi geografi yang digunakan masih belum dimanfaatkan secara maksimal; (5) Sampai saat ini sistem informasi geografi hanya digunakan untuk menampilkan pos polisi dan lampu pengatur lalu lintas.

Untuk memecahkan permasalahan-permasalahan tersebut perlu: (1) membuat perangkat lunak dan keras (sofware dan hardware) untuk dapat memberikan kendali secara langsung terhadap lampu lalu lintas; (2) memberikan informasi jalur alternatif apabila terjadi kemacetan. Di daerah Matraman sampai Senen dengan melihat titik-titik yang muncul di peta yang mengindikasikan terjadinya kemacetan. Dari informasi yang diterima, operator dapat meneruskannya kepada pengguna jalan melalui media LCD; (3) memaksimalkan penggunaan SIG dengan menambah layer baru berupa 
rumah sakit, kantor-kantor pemerintah, dan stasiun pengisian bahan bakar di daerah Matraman sampai Senen.

Tujuan utama penelitian adalah untuk menganalisis dan merancang sistem kendali lampu pengatur lalu lintas yang mampu bekerja secara otomatis maupun dengan manual dengan memberikan prioritas antrian. Sistem ini menggunakan pendeteksi logam (sensor) dan CCTV sebagai alat pemberi informasi mengenai keadaan arus lalu lintas yang berada di sekitar sensor dan CCTV tersebut.

Adapun manfaat yang ingin dicapai adalah: (1) untuk pemetaan - jika seluruh lampu pengatur lalu lintas di DKI Jakarta telah menggunakan sistem ini, alat akan mampu memetakan keadaan arus dan kondisi lalu lintas secara on-line yang dikendalikan oleh Traffic Management Center (TMC). Apabila terjadi kemacetan yang luar biasa (misalnya terjadi banjir, demonstrasi, kebakaran, tawuran, dan lain-lain) pada satu wilayah tertentu, pihak TMC akan dengan mudah mengatur arus lalu lintas yang menuju ke tempat tersebut dengan memblokir hingga kemacetan mencair, dan sekaligus membuka akses jalan ke daerah yang kurang padat; (2) untuk pengendalian - untuk kepentingan kenegaraan, misalnya apabila VIP akan menuju tempat tertentu, pihak TMC dengan mudah mengontrol/mengarahkan jalur mana yang harus dilalui agar dapat mencapai tujuan dengan lancar dan cepat; (3) untuk mendukung TMC dalam memberikan pelayanan kepada para pengguna jalan; (4) untuk menggantikan sebagian besar peran polisi yang bertugas mengatur lalu lintas di lampu lalu lintas. Dengan penggunaan sistem ini maka petugas yang selama ini berjaga di tempat lampu pengatur lalu lintas dapat dialokasikan ke tempat lain; (5) untuk mengurangi tingkat polusi dan menghemat pemakaian bahan bakar.

\section{METODE}

Perancangan Perangkat Keras (Hardware) yang akan dilakukan meliputi: (1) modul sensor sensor hall effect melakukan deteksi terhadap objek logam dalam hal ini kendaraan bermotor. Jika hall effect mendeteksi perubahan medan magnetik (terhalang oleh benda logam), sinyal dari perubahan tersebut akan dikirimkan ke mikrokontroler; (2) modul mikrokontroler - menggunakan MC AT89S51 yang berfungsi untuk mengolah dan mengeksekusi data dengan resolusi 8 bit. Dalam hal ini mikrokontroler digunakan sebagai pengendali dari hardware dan melakukan pengolahan data untuk sensor hall effect ( mengambil nilai 0 dan 1, 0 berarti sensor mati, dan 1 bila sensor aktif) untuk kemudian dikirimkan ke software melalui RS232. Mikrokontroler ini juga berfungsi sebagai penampung program dari komputer; (3) Modul RS232 - menghubungkan PC dengan Mikrokontroler agar data yang dikirim dapat tersinkronisasi. Dalam hal ini RS232 mengirimkan data dari sensor yang telah ditampung oleh mikrokontroler. Dan untuk mengirimkan data dari PC ke hardware; (4) Modul LED - pengaktifan LED pada hardware ini menggunakan metode common katoda. Metode ini mengaktifkan pin LED yang diberi logika "1"; (5) Modul LCD - input-an data dalam bentuk teks yang diterima oleh mikrokontroler dari PC akan dikirim ke LCD dalam bentuk karakter ASCII. LCD tersebut menggunakan resolusi 8 bit, sehingga pengiriman data dapat dilakukan secara serentak. (bila kita mengirimkan satu kalimat, akan langsung tampil satu kalimat juga di layar LCD). 


\section{HASIL DAN PEMBAHASAN}

Berikut diagram sistem yang diusulkan (Gambar 2):

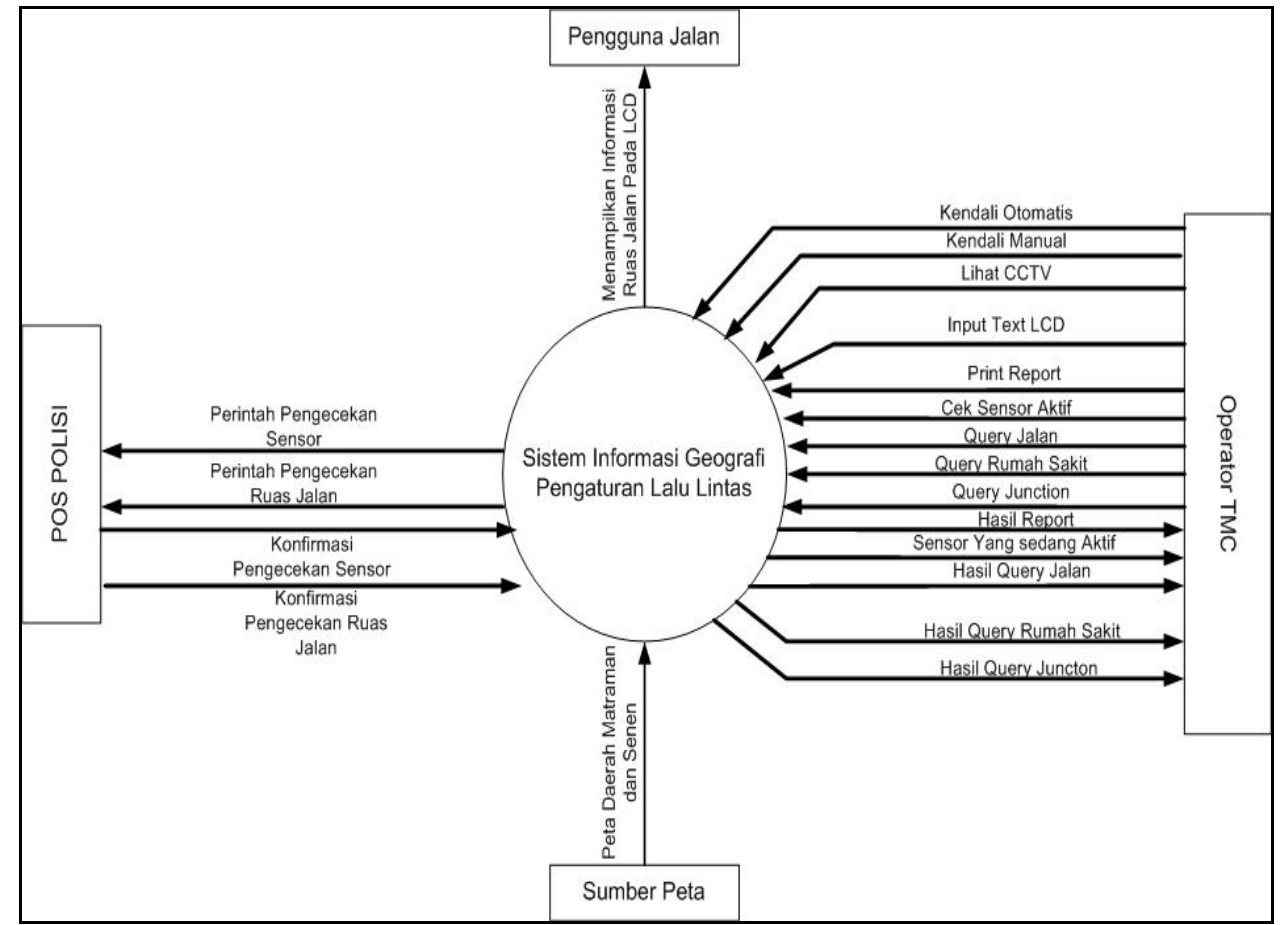

Gambar 2. Data flow diagram sistem yang diusulkan.

Program dirancang untuk dapat berjalan pada stand alone PC maupun pada PC yang tergabung dalam jaringan komputer. Jika ingin menggunakan program aplikasi ini pada stand alone PC, komputer tersebut harus memenuhi persyaratan minimal.

Setelah merancang dan menyelesaikan aplikasi sistem geografi ini, tahap selanjutnya adalah dilakukan evaluasi terhadap sistem dengan melakukan pengujian seperti pemeriksaan kesalahan/error pada program dan pemeriksaan apakah aplikasi sudah cukup user friendly.

Selanjutnya dilakukan presentasi kepada Traffic Management Center untuk mengetahui keunggulan dan kelemahan dari aplikasi ini. Sehingga hasil dari evaluasi ini dapat membantu untuk pengembangan aplikasi ini. Hasil dari presentasi adalah: (1) kelebihan dari aplikasi ini, yaitu: (a) aplikasi ini mampu mendeteksi kepadatan ruas jalan, sehingga memudahkan untuk melakukan pengaturan lalu lintas; (b) tersedia pengaturan secara otomatis dan manual sehingga pihak kepolisian tidak perlu turun langsung ke lapangan; (c) tersedianya fasilitas CCTV untuk membantu memudahkan pemantauan arus lalu lintas di ruas jalan tertentu; (d) berbasiskan peta yang memudahkan pihak kepolisian untuk mengecek daerah persimpangan secara cepat; (e) tersedianya fasilitas pencarian, yang memudahkan pihak kepolisian untuk mencari lokasi seperti rumah sakit, jalan, dll; (f) adanya output berupa report untuk data volume kendaraan harian tiap satuan waktu; (2) kekurangan dari aplikasi ini adalah: (a) hanya mengambil daerah contoh yaitu ruas jalan Matraman - Senen; (b) terkendala biaya untuk diaplikasikan secara real; (c) data kurang akurat karena hanya menggunakan sensor dengan jarak deteksi $1 \mathrm{~cm}$. 


\section{PENUTUP}

Berdasarkan uraian dan pembahasan sebelumnya, dapat diambil kesimpulan bahwa sistem informasi geografi yang dibangun: (1) memberikan kemudahan untuk pengendalian lalu lintas secara langsung; (2) meminimalkan peran polisi dalam mengatur lalu lintas di lapangan ketika terjadi kemacetan; (3) dapat menginformasikan kepada pengguna jalan mengenai situasi arus lalu lintas melalui tampilan LCD; (4) membantu petugas TMC memberikan jalur alternatif kepada pengguna jalan berdasarkan informasi yang di dapatkan dari software; (5) memberikan kemudahan akses bagi perjalanan VIP dengan cara mengendalikan lampu pengatur lalu lintas secara manual melalui software; (6) memberikan data harian untuk kendaraan yang melintas yang didapat dari sensor-sensor pendeteksi logam yang terpasang di sekitar ruas jalan.

\section{DAFTAR PUSTAKA}

Burrough, P.A (1986). Principles of Geographical Information System for Land Resources Assement. London: Buttler and Tanner.

Heywood, Ian, Cornelius, Sarah \& Carver, Steve. (2002). Geographical Information System, (2nd ed.). London: Prentice Hall.

Prahasta, Eddy. (2005). Sistem Informasi Geografis: Konsep-konsep Dasar, (edisi revisi). Bandung: Informatika. 